\title{
A STABILITY-INDICATING AND VALIDATED REVERSE-PHASE HIGH-PERFORMANCE LIQUID CHROMATOGRAPHIC METHOD FOR THE SIMULTANEOUS ESTIMATION OF PHENYLEPHRINE AND FEXOFENADINE IN BULK AND TABLET DOSAGE FORMS
}

\author{
SAI KUMAR B ${ }^{1}$, JYOTHI G ${ }^{2}$, SREENIVASA RAO B ${ }^{1 *}$ \\ ${ }^{1}$ Department of Chemistry, GITAM University, Vishakhapatnam, Andhra Pradesh, India. ${ }^{2}$ Hetero Drugs Ltd., Hyderabad, Telangana, India. \\ Email: saikumarbadam@gmail.com
}

Received: 09 June 2016, Revised and Accepted: 15 June 2016

\section{ABSTRACT}

Objective: A simple and accurate stability indicating reversed-phase high-performance liquid chromatography method was developed and validated for the simultaneous estimation of phenylephrine and fexofenadine in pharmaceutical dosage forms.

Methods: Chromatography was carried out on an Kromasil C-18 column ( $4.6 \mathrm{~mm} \times 250 \mathrm{~mm}, 5 \mu$ particle size) with a isocratic mobile phase composed of ortho phosphoric acid buffer, acetonitrile, $(75: 25 \% \mathrm{v} / \mathrm{v})$ at a flow rate of $1 \mathrm{~mL} /$ minutes. The column temperature was maintained at $30^{\circ} \mathrm{C}$ and the detection was carried out using a photodiode array detector at $210 \mathrm{~nm}$.

Results: The retention times for phenylephrine and fexofenadine were 2.156 minutes and 3.359 minutes, respectively. The percentage recoveries of phenylephrine and fexofenadine were $100.63 \%$ and $99.84 \%$, respectively. The relative standard deviation for assay of tablets was found to be $<2 \%$. The detection and quantification limits were found to be 0.10 and $0.31 \mu \mathrm{g} / \mathrm{mL}$ for phenylephrine and 0.01 and $0.03 \mu \mathrm{g} / \mathrm{mL}$ for fexofenadine, respectively.

Conclusion: Thus, the method was fast, accurate, precise, and sensitive; hence, it can be employed for routine quality control of tablets containing both drugs in quality control laboratories and pharmaceutical industries.

Keywords: Phenylephrine, Fexofenadine, Stability indicating method, Validation method, Reversed-phase high performance liquid chromatography.

(C) 2016 The Authors. Published by Innovare Academic Sciences Pvt Ltd. This is an open access article under the CC BY license (http://creativecommons. org/licenses/by/4. 0/) DOI: http://dx.doi.org/10.22159/ajpcr.2016.v9s2.13371

\section{INTRODUCTION}

Phenylephrine (ACB) is chemically named as 3-[(1R)-1-hydroxy-2(methyl amino) ethyl] phenol (Fig. 1). It is used as a sympathomimetic amine that acts predominantly on $\alpha$-adrenergic receptors. It is mainly used to treat nasal congestion, but may also be useful in treating hypotension and shock, hypotension during spinal anesthesia, prolongation of spinal anesthesia, paroxysmal supraventricular tachycardia, symptomatic relief of external or internal hemorrhoids, and to increase blood pressure as an aid in the diagnosis of heart murmurs [1-3].

Fexofenadine is chemically named as 2-(4-\{1-hydroxy-4[4(hydroxydiphenylmethyl) piperidin-1-yl] butyl\}phenyl)-2methylpropanoic acid (Fig. 2). Fexofenadine hydrochloride (Allegra) is an antihistamine drug used in the treatment of hay fever and similar allergy symptoms. It was developed as a successor of an alternative to terfenadine [4-6]. Fexofenadine, like other second- and third-generation antihistamines, does not readily pass through the blood-brain barrier, and so causes less drowsiness than first-generation histamine receptor antagonists.

Various ultraviolet (UV) and high-performance liquid chromatographic (HPLC) assay methods are also reported in literature for the estimation of phenylephrine and fexofenadine individually and in combination with other drugs [7-12]. According to literature survey, there is no official method for the simultaneous estimation of phenylephrine and fexofenadine by reverse phase-HPLC (RP-HPLC) in combined tablet dosage forms. Hence, an attempt has been made to develop new method for simultaneous estimation and validation of phenylephrine and fexofenadine in tablet formulation in accordance with the ICH guidelines [13].

\section{METHODS}

Chemicals

The reference samples of phenylephrine and fexofenadine were provided as gift samples from Spectrum Pharma Research Solutions, Hyderabad. HPLC grade acetonitrile, HPLC grade methanol, and all other chemicals were obtained from Merck chemical division, Mumbai. HPLC grade water obtained from milli-Q water purification system was used throughout the study. Commercial tablets (Wormazan; dosage: Phenylephrine - $850 \mathrm{mg}$ and fexofenadine - $5 \mathrm{mg}$ ) were purchased from the local pharmacy.

\section{Instrumentation}

RP-HPLC waters 2695 separation module equipped with 2996 Photo diode Array Detector was employed in this method. The Empower 2 software was used for LC peak integration along with data acquisition and data processing. The column used for separation of analytes is Kromasil C18 $(250 \mathrm{~mm} \times 4.6 \mathrm{~mm}, 5 \mu \mathrm{m})$. Mobile phase consisting of orthophosphoric acid buffer:acetonitrile in the ratio of $75: 25 \% \mathrm{v} / \mathrm{v}$ at a flow rate of $1.0 \mathrm{~mL} /$ minutes. It was filtered through $0.45 \mu \mathrm{m}$ nylon filter and sonicated for 5 minutes in ultrasonic bath. Samples were analyzed at $210 \mathrm{~nm}$ at an injection volume of $10 \mu \mathrm{l}$.

\section{Preparation of solutions}

\section{Preparation of phosphate buffer $\mathrm{pH} 4.8$}

One milliliter of orthophosphoric acid was taken in a $1000 \mathrm{~mL}$ volumetric flask, add about $900 \mathrm{~mL}$ of milli-Q water, degas to sonicate, and finally make up the volume with water. 


\section{Phenylephrine stock preparation $(100 \mu \mathrm{g} / \mathrm{mL})$}

Accurately weighed and transferred $2.5 \mathrm{mg}$ of phenylephrine into $25 \mathrm{~mL}$ clean dry volumetric flask, add $17 \mathrm{~mL}$ of diluent (water:methanol - 50:50), then sonicate for 10 minutes, and make up the volume with diluent.

\section{Fexofenadine stock preparation $(1200 \mu \mathrm{g} / \mathrm{mL})$}

Accurately weighed $30 \mathrm{mg}$ of fexofenadine and transferred into $25 \mathrm{~mL}$ clean dry volumetric flask, add $17 \mathrm{~mL}$ of diluent (water:methanol - 50:50), then sonicate for 10 minutes, and make up the final volume with diluent.

\section{Standard preparations}

Phenylephrine standard preparation $(10 \mu \mathrm{g} / \mathrm{mL})$

From the above phenylephrine stock solution, $1 \mathrm{~mL}$ was pipetted out into $10 \mathrm{~mL}$ clean dry volumetric flask and make up the final volume with diluent.

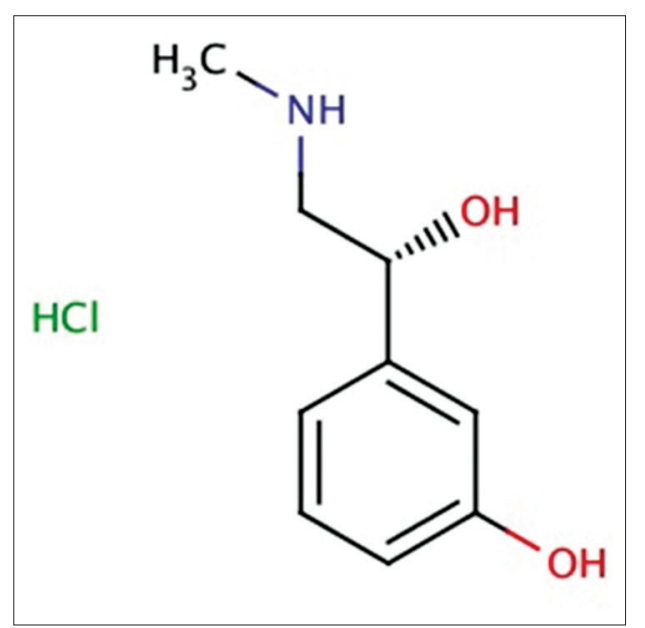

Fig. 1: Chemical structure of phenylephrine

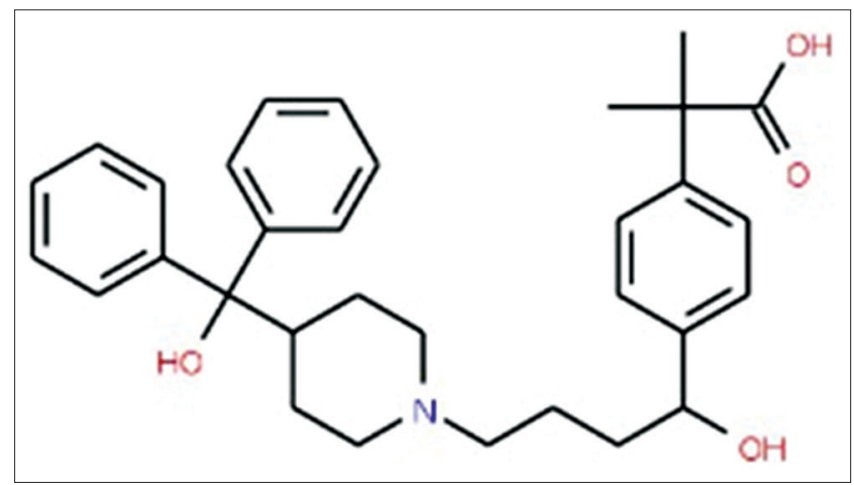

Fig. 2: Chemical Structure of fexofenadine

\section{Fexofenadine standard preparation $(120 \mu \mathrm{g} / \mathrm{mL})$}

From the above fexofenadine stock solution, $1 \mathrm{~mL}$ was pipetted out into a $10 \mathrm{~mL}$ clean dry volumetric flask and make up the final volume with diluent.

\section{Sample preparation}

One tablet weighed and transferred into $25 \mathrm{~mL}$ volumetric flask, $10 \mathrm{~mL}$ diluent added and sonicated for 5 minutes. Further the volume made up with diluent and filtered. Further diluted $1 \mathrm{~mL}$ of filtrate to $10 \mathrm{~mL}$ with diluent and mixed.

\section{Label claim}

Phenylephrine $2.5 \mathrm{mg}$ and fexofenadine $30 \mathrm{mg}$.

\section{Chromatographic condition}

Samples were analyzed at $210 \mathrm{~nm}$ at an injection volume of $10 \mu \mathrm{l}$ and separation was carried out using Kromasil C18 (250 mm×4.6 mm, 5 $\mu \mathrm{m})$ column and orthophosphoric acid buffer:acetonitrile in the ratio of $75: 25 \% \mathrm{v} / \mathrm{v}$ as mobile phase at a flow rate $1.0 \mathrm{~mL} /$ minutes. The proposed method was optimized to give a sharp peak with minimum tailing for phenylephrine and fexofenadine (Fig. 3). The optimized conditions are given in Table 1.

\section{Method development}

To establish and validate an efficient method for analysis of these drugs in pharmaceutical formulations, preliminary tests were performed. Different chromatographic conditions were employed for the analysis of the phenylephrine and fexofenadine in both bulk and pharmaceutical dosage forms. The pure drugs of phenylephrine and fexofenadine were injected into the HPLC system and run using standard organic solvents commonly used for HPLC studied. Water and methanol were tested separately and commonly used for HPLC studies.

In focus to develop good symmetrical peak, water was replaced by phosphate buffer and it was observed that phosphate and acetonitrile gave satisfactory results. This mobile phase system was tried with different proportions and with different flow rates. Finally, the optimal condition of the mobile phase was chose as phosphate buffer:acetonitrile in the ratio of $75: 25 \% \mathrm{v} / \mathrm{v}$. This composition of the mobile phase resolved the two drugs very well. All measurements were carried at ambient temperature of the column. To optimize the flow rate, various flow rates were used. The optimal flow rate was $1 \mathrm{~mL} /$ minute for the presented work.

\section{Method validation}

The validation of the method was carried out as per ICH guidelines [13]. The parameters assessed were specificity, linearity, precision, accuracy, stability, limit of detection (LOD), and limit of quantitation (LOQ).

\section{Specificity}

Specificity is the ability of the analytical method to measure the analyte response in the presence of interferences including degradation products and related substances.

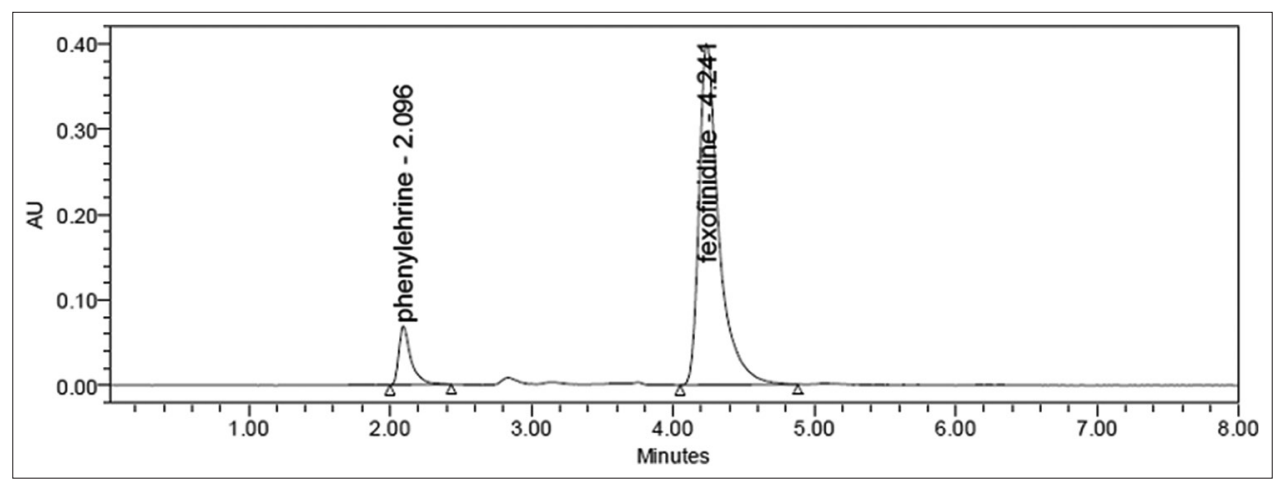

Fig. 3: Standard chromatogram of phenylephrine and fexofenadine 


\section{Accuracy}

The accuracy was determined by calculating the percentage recoveries of phenylephrine and fexofenadine. It was carried out by adding known amounts of each analyte corresponding to three concentration levels $(50 \%, 100 \%$, and $150 \%)$ of the labeled claim to the excipients. At each level, six determinations were performed and the accuracy results were expressed as percent analyte recovered by the proposed method.

\section{Precision}

Precision of an analytical method is usually expressed as the standard deviation. The repeatability studies were carried out by estimating response of phenylephrine and fexofenadine six times. The intraday and interday precision studies (intermediate precision) were carried out by estimating the corresponding responses three times on the same day and on three different days for three different concentrations and the results are reported in terms of relative standard deviation (RSD).

\section{Linearity}

The purpose of the test for linearity is to demonstrate that the entire analytical system (including detector and data acquisition) exhibits a linear response and is directly proportional over the relevant concentration range for the target concentration of the analyte. The linear regression data for the calibration plot are indicative of a good linear relationship between peak area and concentration over a wide range. The correlation coefficient was indicative of high significance.

\section{Robustness}

Robustness of the method was investigated under a variety of conditions including changes of composition of buffer in the mobile phase, flow rate, and temperature. This deliberate change in the method has no effect on the peak tailing, peak area, and theoretical plates, and finally the method was found to be robust.

\section{$\angle O D$ and $L O Q$}

The LOD can be defined as the smallest level of analyte that gives a measurable response and LOQ was determined as the lowest amount of

\section{Table 1: Optimized chromatographic conditions}

\begin{tabular}{ll}
\hline Parameter & Condition \\
\hline Mobile phase & $\begin{array}{l}\text { Orthophosphoric acid buffer:acetonitrile:(75:25\% } \\
\text { v/v) pH adjusted to } 4.8\end{array}$ \\
Column & Kromasil $250 \mathrm{~mm} \times 4.6 \mathrm{~mm}, 5 \mu$ \\
Wavelength & $210 \mathrm{~nm}$ \\
Flow rate & $1.0 \mathrm{~mL} /$ minutes \\
Injection & $10 \mu \mathrm{L}$ \\
volume & \\
Runtime & 6 minutes \\
Diluent & Water:acetonitrile (50:50) \\
\hline
\end{tabular}

analyte that was reproducibly quantified. These two parameters were calculated using the formula based on the standard deviation of the response and the slope. LOD and LOQ were calculated using equations:

- $\quad \mathrm{LOD}=3.3 \times \mathrm{s} / \mathrm{S}$ and

- $\mathrm{LOQ}=10 \times \mathrm{S} / \mathrm{S}$.

Where $\mathrm{s}=$ Standard deviation, $\mathrm{S}=$ Slope of the calibration curve.

Assay of phenylephrine and fexofenadine in tablet

Assay of marketed product was carried out using the developed method. Sample solutions were prepared and injected into RP-HPLC system. The sample solution was scanned at $210 \mathrm{~nm}$. The $\%$ drug estimated was found to be 99.86 for phenylephrine and 99.77 for fexofenadine. The chromatogram showed two single peaks of phenylephrine and fexofenadine was observed with retention times of 2.137 and 3.343 minutes (Fig. 4).

\section{Forced degradation studies}

Stress studies are performed according to ICH guidelines under conditions of hydrolysis (acidic and alkaline), photolysis, oxidation, and thermal studies.

\section{Oxidation}

To $1 \mathrm{~mL}$ of stock solution of phenylephrine and fexofenadine, $1 \mathrm{~mL}$ of $20 \%$ hydrogen peroxide $\left(\mathrm{H}_{2} \mathrm{O}_{2}\right)$ was added separately. The solutions were kept for 30 minutes at $60^{\circ} \mathrm{C}$. For HPLC study, the resultant solution was diluted to obtain 850 and $5 \mu \mathrm{g} / \mathrm{mL}$ solutions and $10 \mu \mathrm{l}$ solutions were injected into the system and the chromatograms were recorded to assess the stability of sample.

\section{Acid degradation studies}

To $1 \mathrm{~mL}$ of stock solution phenylephrine and fexofenadine, $1 \mathrm{~mL}$ of $2 \mathrm{~N}$ hydrochloric acid was added and refluxed for 30 minutes at $60^{\circ} \mathrm{C}$. The resultant solution was diluted to obtain 850 and $5 \mu \mathrm{g} / \mathrm{mL}$ solutions and $10 \mu \mathrm{l}$ solutions were injected into the system and the chromatograms were recorded to assess the stability of sample.

\section{Alkali degradation studies}

To $1 \mathrm{~mL}$ of stock solution phenylephrine and fexofenadine, $1 \mathrm{~mL}$ of $2 \mathrm{~N}$ sodium hydroxide was added and refluxed for 30 minutes at $60^{\circ} \mathrm{C}$. The resultant solution was diluted to obtain 850 and $5 \mu \mathrm{g} / \mathrm{mL}$ solutions and $10 \mu \mathrm{l}$ solutions were injected into the system and the chromatograms were recorded to assess the stability of sample.

\section{Dry heat degradation studies}

The standard drug solution was placed in oven at $105^{\circ} \mathrm{C}$ for $6 \mathrm{hrs}$ to study dry heat degradation. For HPLC study, the resultant solution was diluted to 850 and $5 \mu \mathrm{g} / \mathrm{mL}$ solutions and $10 \mu \mathrm{l}$ solutions were injected into the system and the chromatograms were recorded to assess the stability of the sample.

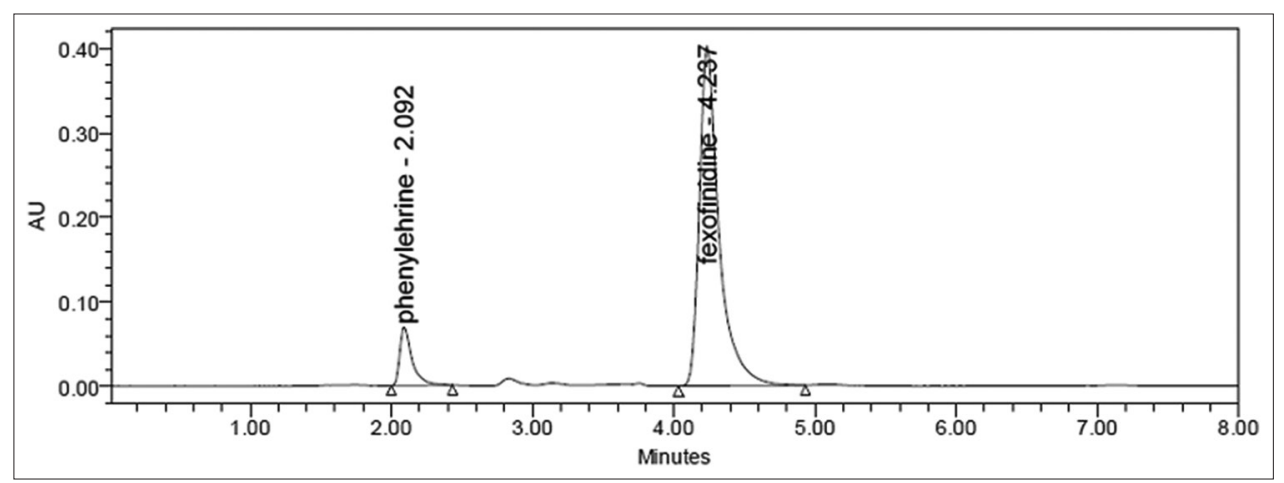

Fig. 4: A typical chromatogram of phenylephrine and fexofenadine in tablet dosage form 


\section{Photo stability studies}

The photochemical stability of the drug was also studied by exposing the 850 and $5 \mu \mathrm{g} / \mathrm{mL}$ solutions to UV Light by keeping the beaker in UV chamber for 7 days or 200 watt hrs $/ \mathrm{m}^{2}$ in photo stability chamber. For HPLC study, the resultant solution was diluted to obtain 850 and $5 \mu \mathrm{g} / \mathrm{mL}$ solutions and $10 \mu \mathrm{l}$ solutions were injected into the system and the chromatograms were recorded to assess the stability of sample.

\section{RESULTS AND DISCUSSIONS}

To establish and validate an efficient method for analysis of these drugs in pharmaceutical formulations, preliminary tests were performed. Different chromatographic conditions were employed for the analysis of the phenylephrine and fexofenadine in both bulk and pharmaceutical dosage forms.

Table 2: Results of forced degradation studies

\begin{tabular}{|c|c|c|c|c|c|}
\hline \multirow{2}{*}{$\begin{array}{l}\text { Serial } \\
\text { number }\end{array}$} & \multirow{2}{*}{ Injection } & \multicolumn{2}{|c|}{ Phenylephrine \% } & \multicolumn{2}{|c|}{ Fexofenadine \% } \\
\hline & & Assay & Degradation & Assay & Degradation \\
\hline 1 & $\begin{array}{l}\text { Acid } \\
\text { degradation }\end{array}$ & 96.37 & 3.63 & 95.81 & 4.19 \\
\hline 2 & $\begin{array}{l}\text { Base } \\
\text { degradation }\end{array}$ & 96.88 & 3.12 & 96.22 & 3.78 \\
\hline 3 & Peroxide & 98.90 & 1.10 & 97.91 & 2.09 \\
\hline 4 & $\begin{array}{l}\text { Thermal } \\
\text { degradation }\end{array}$ & 99.60 & 0.40 & 99.16 & 0.84 \\
\hline 5 & UV degradation & 99.41 & 0.59 & 99.42 & 0.58 \\
\hline 6 & $\begin{array}{l}\text { Neutral } \\
\text { degradation }\end{array}$ & 99.66 & 0.34 & 99.93 & 0.07 \\
\hline
\end{tabular}

Table 3: Precision method of proposed RP-HPLC method

\begin{tabular}{lll}
\hline Drug & Mean area & RSD \% \\
\hline Phenylephrine & 486451 & 0.4 \\
Fexofenadine & 2974450 & 0.6 \\
\hline
\end{tabular}

RP-HPLC: Reverse phase high-performance liquid chromatographic, RSD: Relative standard deviation

Table 4: Percentage recovery data for phenylephrine and fexofenadine

\begin{tabular}{llll}
\hline Drug & Spiked level \% & Recovery \% & RSD \% \\
\hline Phenylephrine & 50 & 99.96 & 0.7 \\
& 100 & 100.36 & 1.2 \\
Fexofenadine & 150 & 101.17 & 0.7 \\
& 50 & 100.06 & 0.7 \\
& 100 & 100.34 & 1.1 \\
& 150 & 99.77 & 0.6 \\
\hline
\end{tabular}

RSD: Relative standard deviation

Table 5: Linearity results for phenylephrine and fexofenadine

\begin{tabular}{llllll}
\hline $\begin{array}{l}\text { Serial } \\
\text { number }\end{array}$ & Phenylephrine & & & Fexofenadine \\
\cline { 2 - 3 } \cline { 5 - 6 } & $\begin{array}{l}\text { Concentration } \\
(\boldsymbol{\mu g} / \mathbf{m l})\end{array}$ & $\begin{array}{l}\text { Peak } \\
\text { area }\end{array}$ & & $\begin{array}{l}\text { Concentration } \\
(\boldsymbol{\mu g} / \mathbf{m l})\end{array}$ & $\begin{array}{l}\text { Peak } \\
\text { area }\end{array}$ \\
\hline 1 & 2.5 & 121122 & 30 & 7317141 \\
2 & 5 & 239068 & 60 & 1515761 \\
3 & 7.5 & 356766 & 90 & 2277363 \\
4 & 10 & 482515 & 120 & 2958025 \\
5 & 12.5 & 604482 & 150 & 3738455 \\
6 & 15 & 704793 & 180 & 4469025 \\
\hline
\end{tabular}

Finally, the analysis was performed according to ICH guidelines using orthophosphoric acid buffer:acetonitrile in the ratio of $75: 25 \% \mathrm{v} / \mathrm{v}$ at a flow rate $1.0 \mathrm{~mL} /$ minute. Samples were analyzed at $210 \mathrm{~nm}$ at an injection volume of $10 \mu \mathrm{l}$ and separation was carried using Kromasil C18, $(250 \mathrm{~mm} \times 4.6 \mathrm{~mm}, 5 \mu \mathrm{m})$ column.

Forced degradation studies were performed to establish the stability indicating property and specificity of the proposed method. Degradation studies were carried out under conditions of hydrolysis, dry heat, oxidation, UV light, and photolysis, and the drug substances were degraded in all conditions. Acid and base hydrolysis was performed by exposing the drug substances with $2 \mathrm{~N} \mathrm{HCl}$ and $2 \mathrm{~N} \mathrm{NaOH}$ at $60^{\circ} \mathrm{C}$ for 30 minutes and it was showed degradation of phenylephrine and fexofenadine with degraded products peak at retention time 2.079 and 5.175 minutes, respectively. Degradation studies under oxidative conditions were performed by heating the drug sample with $20 \% \mathrm{H}_{2} \mathrm{O}_{2}$ at $60^{\circ} \mathrm{C}$ and degraded product peaks were observed. Both phenylephrine and fexofenadine are sensitive to acid and alkali, and there was no degradation occurs under UV light and thermal conditions. The results of forced degradation studies are given in Table 2.

Precision was evaluated by a known concentration of phenylephrine and fexofenadine was injected six times and corresponding peaks were recorded and \% RSD was calculated and found within the limits. The low \% RSD value was indicated that the method was precise and reproducible and the results are shown in Table 3.

Accuracy of the method was proved by performing recovery studies on the commercial formulation at $50 \%, 100 \%$, and $150 \%$ levels. The percentage recoveries of phenylephrine and fexofenadine range from $99.84 \%$ to $100.63 \%$ in simultaneous equation method and the results are shown in Table 4.

Linearity was established by analyzing different concentrations of phenylephrine and fexofenadine respectively. The calibration curve was plotted with the area obtained versus concentration of both

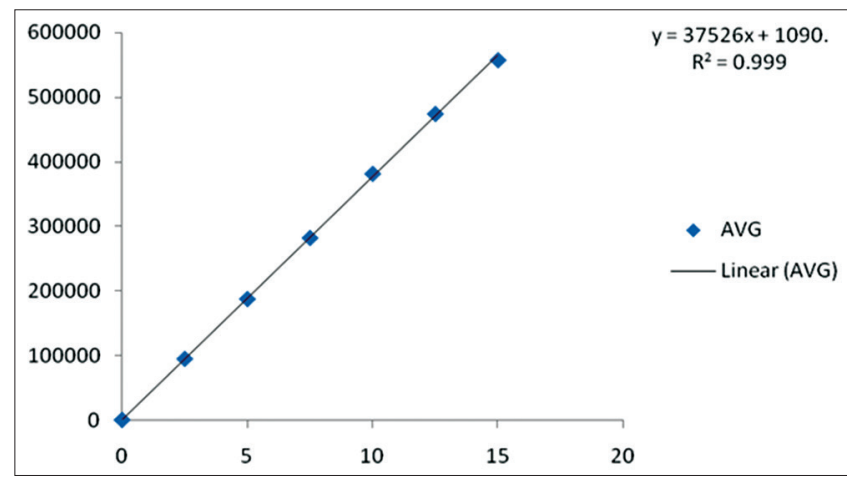

Fig. 5: Linearity curve of phenylephrine

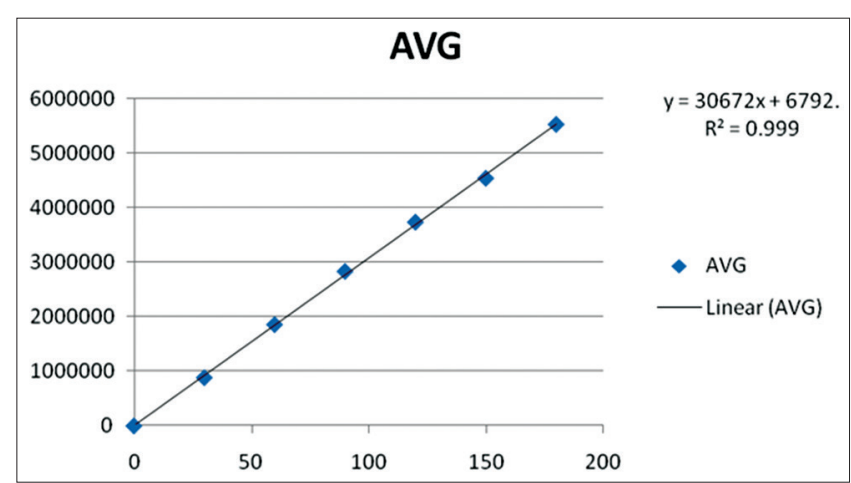

Fig. 6: Linearity curve of fexofenadine 
Table 6: Robustness data for phenylephrine and fexofenadine

\begin{tabular}{|c|c|c|c|c|c|}
\hline \multirow[t]{2}{*}{ Parameters } & \multirow[t]{2}{*}{ Changed condition } & \multicolumn{2}{|l|}{ Mean peak area } & \multicolumn{2}{|l|}{ USP plate count } \\
\hline & & Phenylephrine & Fexofenadine & Phenylephrine & Fexofenadine \\
\hline \multirow[t]{2}{*}{ Flow rate $(\mathrm{mL} / \mathrm{min})$} & $0.9 \mathrm{ml}$ & 532958 & 3010741 & 5571 & 6553 \\
\hline & $1.1 \mathrm{ml}$ & 450777 & 2571476 & 5239 & 6551 \\
\hline \multirow[t]{3}{*}{ Temperature $( \pm 5)$} & $25^{\circ} \mathrm{C}$ & 469096 & 2665873 & 5878 & 8857 \\
\hline & $30^{\circ} \mathrm{C}$ & 485692 & 2972499 & 5555 & 6489 \\
\hline & $35^{\circ} \mathrm{C}$ & 455342 & 2609021 & 5328 & 9367 \\
\hline \multirow[t]{3}{*}{ Mobile phase $( \pm 5 \%)$} & $70: 30 \% \mathrm{v} / \mathrm{v}$ & 486123 & 2791762 & 5273 & 6573 \\
\hline & $75: 25 \% \mathrm{v} / \mathrm{v}$ & 485692 & 2972499 & 5555 & 6489 \\
\hline & $80: 20 \% \mathrm{v} / \mathrm{v}$ & 495450 & 2791810 & 4521 & 6331 \\
\hline
\end{tabular}

USP: United States Pharmacopeia

Table 7: Results of LOD and LOQ for phenylephrine and fexofenadine

\begin{tabular}{lll}
\hline Drug & LOD $(\mu \mathrm{g} / \mathrm{ml})$ & LOQ $(\mu \mathrm{g} / \mathbf{m l})$ \\
\hline Phenylephrine & 0.01 & 0.03 \\
Fexofenadine & 0.08 & 0.24 \\
\hline
\end{tabular}

LOD: Limit of detection, LOQ: Limit of quantitation

phenylephrine and fexofenadine (Figs. 5 and 6). In the present study, six concentrations were chosen ranging between 2.5 and $15 \mu \mathrm{g} / \mathrm{mL}$ of phenylephrine and $30-180 \mu \mathrm{g} / \mathrm{mL}$ of fexofenadine.

The regression equation and correlation coefficient for phenylephrine and fexofenadine were found to be $y=47494 x+2190$. And $R^{2}=0.9990$ and $y=24837 x+6185$. And $R^{2}=0.9990$, respectively, and results are given in Table 5.

Robustness of the method is the ability of the method to remain unaffected by small deliberate changes in parameters such as flow rate, mobile phase composition and column temperature. To study the effect of flow rate of the mobile phase, it was changed to 0.1 units from 1.0 to $0.9 \mathrm{~mL}$ and $1.1 \mathrm{~mL}$. The effect of column temperature was also checked by changing the temperature to $\pm 5^{\circ} \mathrm{C}$. This deliberate change in the above parameters has no significant effect on chromatographic behavior of the samples and results are given in Table 6 .

LOD and LOQ of phenylephrine and fexofenadine were evaluated based on RSD of the response and slope of the calibration curve. The detection limits were found to be 0.01 and $0.08 \mu \mathrm{g} / \mathrm{mL}$ for phenylephrine and fexofenadine, respectively. The quantitation limits were found to be 0.08 and $0.24 \mu \mathrm{g} / \mathrm{mL}$ for phenylephrine and fexofenadine, respectively. The results are given in Table 7 .

\section{CONCLUSION}

A new stability-indicating RP-HPLC method has been developed for the estimation of phenylephrine and fexofenadine in bulk and pharmaceutical dosage forms. The developed method was validated, and it was found to be simple, sensitive, precise, and robust and it can be used for the routine analysis of phenylephrine and fexofenadine in both bulk and pharmaceutical dosage forms. The forced degradation studies were carried out in accordance with ICH guidelines and the results revealed suitability of the method to study stability of phenylephrine and fexofenadine under various degradation conditions such as acid, base, oxidative, thermal, UV, and photolytic degradations. Finally, it was concluded that the method is simple, sensitive, and has the ability to separate the drug from degradation products and excipients found in the dosage form.

\section{REFERENCES}

1. Available from: http://www.en.wikipedia.org/wiki/Phenylephrine.

2. Available from: http://www.scbt.com/datasheet-CAS 61-76-7 phenylephrine.html.

3. Available from: http://www.drugbank.ca/drugs/DB00388 (APRD00365).

4. Available from: http://www.en.wikipedia.org/wiki/Fexofenadine.

5. Available from: http://www.scbt.com/datasheet - CAS 83799-24-0. html.

6. Available from: http://www.drugbank.ca/drugs/DB00950 (APRD00349)

7. Bhushan B, Baghel US, Singh R, Kumar Y. RP-HPLC method development for the estimation of levocetirizine and phenylephrine hydrochloride in combined dosage form. Int $\mathrm{J}$ Pharm Med Res 2013;1(2):85-90.

8. Nanaware DA, Bhusari VK, Dhaneshwar SR. Validated HPLC method for simultaneous quantitation of levocetrizine dihydrochloride and phenylephrine hydrochloride in bulk drug and formulation. IAJPR 2013;3(5):3484-349.

9. Buchupalli P, Medidi S. RP-HPLC method for the simultaneous estimation of ambroxol hydrochloride and fexofenadine hydrochloride in bulk and in a tablet mixture. J Appl Pharm Sci 2015;5(2):74-80.

10. Patel KB, Thula KC, Maheshwari DG. Stability indicating HPLC method for simultaneous estimation of ciprofloxacin and phenylephrine in pharmaceutical dosage form. Pharmacophore 2014;5(2):262-72.

11. Pankhaniya M, Patel P, Shah JS. Stability-indicating HPLC method for simultaneous determination of montelukast and fexofenadine hydrochloride. Indian J Pharm Sci 2013;75(3):284-90.

12. Wankhede SB, Lad KA, Chitlange SS. Development and validation of UV-spectrophotometric methods for simultaneous estimation of cetirizine hydrochloride and phenylephrine hydrochloride in tablets. Int J Pharm Sci Drug Res 2012;4(3):222-6.

13. ICH Q2B. Guidelines on validation of analytical procedure Methodology. Fed Regist 1996;60:27464. 